Schneider · Herget

Streitwert-Kommentar 



\title{
Streitwert Kommentar
}

für Zivilprozess und

FamFG-Verfahren

\author{
begründet von \\ Dr. Egon Schneider $†$
}

fortgeführt von

Kurt Herget

bearbeitet von

Norbert Schneider

Rechtsanwalt, Neunkirchen-Seelscheid

Ralf Kurpat

Vors. Richter am Landgericht Bonn

Norbert Monschau

Rechtsanwalt, Fachanwalt für

Miet- und Wohnungseigentumsrecht

Erftstadt

Mark Noethen, LL.M.

Richter am Oberlandesgericht Köln

Lotte Thiel

Rechtsanwältin,

Fachanwältin für Familienrecht Koblenz

14. neubearbeitete und erweiterte Auflage

2016

\section{ottoschmidt}




\section{Zitierempfehlung:}

Bearbeiter in Schneider/Herget, Streitwert-Kommentar, 14. Aufl., Rn. ...

Bibliografische Information

der Deutschen Nationalbibliothek

Die Deutsche Nationalbibliothek verzeichnet diese

Publikation in der Deutschen Nationalbibliografie; detaillierte bibliografische Daten sind im Internet über http://dnb.d-nb.de abrufbar.

Verlag Dr. Otto Schmidt KG

Gustav-Heinemann-Ufer 58, 50968 Köln

Tel. 02 21/9 37 38-01, Fax 02 21/9 37 38-943

info@otto-schmidt.de

www.otto-schmidt.de

ISBN 978-3-504-47092-0

C2016 by Verlag Dr. Otto Schmidt KG, Köln

Das Werk einschließlich aller seiner Teile ist urheberrechtlich geschützt. Jede Verwertung, die nicht ausdrücklich vom Urheberrechtsgesetz zugelassen ist, bedarf der vorherigen Zustimmung des Verlages. Das gilt insbesondere für Vervielfältigungen, Bearbeitungen, Übersetzungen, Mikroverfilmungen und die Einspeicherung und Verarbeitung in elektronischen Systemen.

Das verwendete Papier ist aus chlorfrei gebleichten Rohstoffen hergestellt, holz- und säurefrei, alterungsbeständig und umweltfreundlich.

Einbandgestaltung: Jan P. Lichtenford, Mettmann

Satz: WMTP, Birkenau

Druck und Verarbeitung: Kösel, Krugzell

Printed in Germany 